IP Periodica Polytechnica

Social and Management

Sciences

24(1), pp. 34-40, 2016

DOI: $10.3311 /$ PPso. 8069

Creative Commons Attribution (i)

RESEARCH ARTICLE

\section{Linking SMEs Profitability to Brand Orientation and Market-Sensing Capability: A Service Sector Evidence}

\author{
Christian Nedu Osakwe ${ }^{1 *}$, Miloslava Chovancova ${ }^{1}$, \\ Benson U. Ogbonna ${ }^{2}$
}

Received 11 March 2015; accepted 17 April 2015

\begin{abstract}
The key question among policy makers and marketing scholars alike is 'how can SMEs become more financially viable?' bearing in mind that we now live in a highly globalized society that is driven by technological, social and economic forces. Consequently, for SMEs to become more financially viable in the changing business landscape, it becomes more imperative now than ever before for this set of enterprises to develop some core business orientations and/or capabilities, particularly that of brand orientation and market-sensing capability. Against this backdrop, the current article examines the role of brand orientation and market-sensing capability in relation to the profitability of SMEs in the context of a financial intermediation sector. Based on the findings from 119 surveyed financial services SMEs in one of Africa's largest economies, we have empirical support that both brand orientation and market-sensing capability contribute significantly to SMEs profitability. Our results demonstrate the need for SMEs in the African financial intermediation sector to develop an 'inhouse' branding culture that takes into cognizance 'local' market conditions, and more particularly employee involvement. More so, SMEs should endeavour to develop market-sensing capability given that this unique capability is key to unlocking both present and future marketing opportunities.
\end{abstract}

\section{Keywords}

Africa, brand orientation, market-sensing capability, profitability, financial service sector, SMEs

\footnotetext{
${ }^{1}$ Department of Management and Marketing,

Faculty of Management \& Economics,

Tomas Bata University in Zlin, CzechRepublic

${ }^{2}$ Department of Marketing, University of Port Harcourt,

Rivers State, Nigeria

${ }^{*}$ Corresponding author, e-mail: osakwe@fame.utb.cz
}

\section{Introduction}

There appears to be a general consensus among marketing scholars and practitioners alike about the role of branding to enterprises' marketing competitiveness. Creating a strong brand in the marketplace is inherently seen as one of the key success factors for achieving a competitive edge in the marketplace; thus guaranteeing a firm's long term financial profitability (Aaker, 1996; Balmer and Greyser, 2006; Kapferer, 2008). At the heart and soul of creating a strong and successful brand in the marketplace is brand orientation. From a projective branding paradigm viewpoint, brand orientation is an internalized firm-based culture that takes into cognizance the elements of branding in the firm's overall business strategy (Mitchell, Hutchinson \& Bishop, 2012; Urde, 1999). That is, the firm's understanding of the branding concept becomes highly strategically infused with its marketing culture, strategic planning and decision-making (Gromark and Melin, 2011).

Thus, for any profit-driven firm, particularly an SME that seeks market prominence, the SME's owner/manager brand orientation (BO) attitude will significantly play a critical role as to whether an enterprise (product, service or corporate) brand will be a success or not in the marketplace. In the same vein, for an enterprise to adapt to changing market dynamics in its industry, exploit existing market opportunities, take advantage of new market opportunities and more importantly, create a superior financial value proposition in the marketplace, such an enterprise is expected to strategically leverage on 'outside-in' capabilities, more particularly that of market-sensing capability (Day, 1994).

In a nutshell, the current study is grounded in the Resourcebased View (RBV) theory of the firm which posits that for enterprises to gain a competitive edge in the marketplace, they must first seek to develop firm-based strategic resources that are not only valuable and rare but also very difficult for rival enterprises to replicate and, more importantly these resources must be 'immobile' to a great degree (Barney, 2001). Some other authors have further extended this concept to include the dynamic capabilities view (DCV) of a firm (c.f. Teece, 2007).

Thus, drawing from the perspectives of the RBV ofthe firm, we further examine how enterprises' strategic intents and/or choices 
impact directly on their financial standings in the marketplace. The focus of this study is on SMEs that are operating within the financial intermediation sector of Africa's largest marketplace Nigeria. More specifically, this study is aimed at investigating the nature of the form of relationship between brand orientation, market-sensing capability and SMEs profitability in the context of financial services firms. We further explore if there is a complementarity between brand orientation and market-sensing capability and how this synergy might impact directly on financial services SMEs profitability. To the best of our knowledge, this is the first empirical work that will be testing this nature of complementary relationship in the marketing literature. Thus, our paper adds to the existing knowledge base in the business field, particularly on how firm-based strategic resources impact on SMEs financial performance in a highly under-explored context. In addition, this is arguably the first quantitative SMEs marketing study in Nigeria that is using predictive (soft) modeling. In this instance, Partial Least Squares (PLS) Path Modeling, otherwise popularly referred to as PLS-SEM. On the whole, this article fills an important void in scholarly literature.

This empirical paper is further outlined as follows. The next section covers related literature and hypotheses development. The third section focuses on the research methods used in the context of the study while the subsequent section presents the research findings. We wrap up this paper by presenting a detailed discussion, study's implications, limitations, future research directions as well as the concluding remarks in the fifth section.

\section{Theoretical Background and Hypotheses Development}

\subsection{SMEs Development and Profitability}

More importantly, we do like to stress that our definition or categorisation of SMEs tally with the World Bank's definition of SMEs as enterprises employing between 10 249 employees. Moreover, the research search light focuses 'squarely' on financial services SMEs - micro finance banks (MFBs), finance houses, acceptance/discount houses, and insurance-related companies. These small and medium-sized financial services providers more often than not provide the essential financial services that are needed by both the Middleof-the-Pyramid (MoP) and Bottom-of-the-Pyramid (BoP) market segments in the developing world.

According to Cook and Nixson (2000), the significant contributions of SMEs to the economic development of the developing world have begun to attract interest from the policy makers of these countries. Undeniably, SMEs and micro enterprises are the backbone of the African economy, particularly the Nigerian economy. It is also true that most of these enterprises in Nigeria are presently faced with institutional constraints, resource constraints as well as poor coordination of marketing activities. As such, a majority of these enterprises had remained financially stagnated for a long time.
Some previous studies (Huang and Brown, 1999; Krake, 2005) have identified marketing-related challenges as the major bane of SMEs financial performance. Further, Kotler and Keller (2006) assert that for any profit-seeking firm to continuously make profit in the marketplace, it must seek unique ways of delivering superior customer value amidst the competition. Thus, it becomes more imperative now than ever before for SMEs to possess some core strategic orientations and/or capabilities, particularly that of brand orientation and market-sensing capability in order to remain financially profitable. Recall, that profitability is a measure of value to show if a company is doing well or not (Ogbonna and Ogwo, 2013). In line with extant literature (c.f. Baker and Sinkula, 2009), our measure of profitability in this study is in the subjective measure given that both subjective and objective measures have been found to be strongly correlated together. More so, these firms by default hardly disclose their true financial figures to 'outsiders'. Thus, we believe that a perceptual measure of SMEs profitability will to a large extent reflect their 'true' profitability position.

\subsection{Brand Orientation and SMEs Profitability}

A brand is often perceived as a mark of distinctiveness. Arguably, it could be seen as a multidimensional construct that captures the whole essence of a firm and, in turn sets a firm apart from its rivals. Thus, having a successful brand in the marketplace is very likely to add to a firm's competitive strength, financial profitability and long-term growth strategy (Keller and Lehmann, 2006; Kapferer, 2008). Brand orientation (BO) in a firm is perceived as an organisational mindset that takes into cognizance the strategic role of the brand in adding value to the firm (Urde, 1999).

Thus, the emphasis is for organisations to develop the right mindset for building a long-lasting brand in the marketplace. Building at Urde's (1999) scholarly work, some authors (e.g., see Baumgarth, 2010; Wong and Merrilees, 2008) denote the centrality of the role of BO in a firm's competitive strategy. Lately, there has been an empirical support linking brand orientation directly to the profitability of firms (see Gromark and Melin, 2011). Similarly, in a related study conducted in two EU countries (Finland and Hungary) by Laukkanen et al. (2013), the findings show that BO has a direct linkage to SMEs brand and market performance. In line with these findings, we hypothesize that:

H1: The higher the leverage on $\mathrm{BO}$, the higher will be the profitability of SMEs.

\subsection{Market-Sensing Capability and SMEs Profitability}

According to Day (1994), market-sensing capability (MKTSC) pertains to a firm's capacity to have a deeper insight and understanding of its macro market environment as it presumably impacts on the firm's customers, competitors and other strategic business partners. Day (1994) emphasizes the need for 
firms to develop the requisite knowledge with skills-set that is relevant for understanding the changing business dynamics in a particular industry and/or market segment. Thus, organisational learning becomes a strategic resource for firms to be acquainted with this kind of capability. Moreover, developing MKTSC in a highly competitive sector, like that of the financial intermediation sector, is perceived to lead to superior customer value and financial performance (Day, 1994; 2002; Santos-Vijande et al., 2012). Based on the foregoing, we hypothesize that:

H2: The higher the leverage on MKTSC, the higher will be the profitability of SMEs.

\subsection{The Synergistic Effect of BO with MKTSC and SMEs Profitability}

A number of research streams in the marketing field seem to suggest of the complementarity (synergy) between branding as a marketing concept, in this instance, BO and MKTSC (e.g., see Morgan, Slotegraaf and Vorhies, 2009; Ewing and Napoli as cited in Balmer, 2010). Similarly, Reid, Luxton and Mavondo (2005) opine that market-sensing capability offers firms invaluable insights on how they could differentiate and manage their brands to become more successful in the competitive business landscape. Although both BO and MKTSC are presumably two distinct strategic levers, they are equally related levers that could be strategically and simultaneously deployed together in order to bolster a firm's competitive dynamics and ultimately its financial outcomes in the marketplace.

We further argue that the 'interconnectedness' of firm-based strategic resources is key to unlocking potential financial opportunities for growth aspiring SMEs in the financial industry. More so, drawing from the perspective of the RBV theory of the firm, we argue strongly that these are two similar strategic resources that fully complement each other. In the present study, we do not see either strategic resource as an independent moderator, but rather as complementary firm-based strategic resources that could as well augment the profitability of SMEs in the financial intermediation sector. Thus, in line with a couple of scholarly literature that investigated similar complementarity between two strategic firm-based resources and enterprise financial performance (Baker and Sinkula, 2009; Ngo and O' Cass, 2012); we further hypothesize the following relationships:

H3a: The higher the leverage on BO by SMEs, the higher will be the leverage on MKTSC, and vice versa. That is both $\mathrm{BO}$ and MKTSC will covary together.

H3b: In addition to their individual effects, the complementarity (synergy) between BO and MKTSC will significantly contribute to SMEs profitability.

\subsection{Control Variables}

Relative Firm Size: The effects of firm size (in terms of staff strength) on firm profitability have generated mixed results ranging from those supporting a positive relationship among these variables to those opposing it. Several arguments favour firms with a relatively large number of employees in attaining higher financial performance. Enterprises with more staff strength are more likely to exploit economies of scale, thus, it is expected that these enterprises will be more competitive and profitable (Serrasqueiro and Nunes, 2008).

Employee Motivation/Morale: From a theoretical standpoint, a highly motivated workforce is a sine qua non for organisational productivity as well as enterprise financial profitability. How an enterprise motivates or incentivises its workforce is beyond the scope of the present study, rather what is pertinent to this study is to connect and control the effect of such a relationship to enterprise profitability.

Enterprise Investment in Staff Training/ Development: Prior studies (c.f. Storey and Westhead, 1994) have shown that any firm that wants to be financially successful in the marketplace would have to invest in employee training and/or development. However, to date many SMEs, particularly those in African countries still view employee training as an extra cost that somewhat impacts negatively on their 'marginal' income. This may be quite understandable given the high staff turnover in SMEs. Nonetheless, for financial services SMEs in particular to fully exploit and explore marketing opportunities and in tandem bolster their profitability, these enterprises would have to invest in staff training/development.

Considering the likely impacts of the control variables (relative firm size, employee motivation/morale, and investment in staff training/development) on SMEs profitability, albeit from the standpoint of extant literature, we expect that this collection of control variables will contribute significantly to the profitability of SMEs in the financial services sector.

\section{Research Method}

\subsection{Sampling and Data Collection}

The target population of this study constituted financial services firms that are operating in Nigeria's financial capital (Lagos State), Rivers State (Port Harcourt) as well as the political seat of power, FCT Abuja. Lagos State alone accounts for the highest concentration of enterprises in this sector. From the estimated population figures of 512 registered enterprises in the three states and/or cities (SMEDAN/NBS, 2010); we could only administer roughly about 230 close-ended questionnaires to the study participants, especially as a result of the cut-off time of the study and resource constraints. Also, it was quite challenging for us to get the contact details of some of these enterprises due to the non-availability of a reputable company databank and/or yellow page(s) in the country of study. We manually searched for most of these enterprises' contacts using archival records, personal contacts and Internet search.

Despite the challenges, we were still able to get a feedback from 155 SMEs operating in the Nigerian financial intermediation sector. The questionnaires were administered 
to enterprises, usually in the form of hard copies and through proxies. Given that enterprise is the unit of analysis in our study, we thus relied on the information supplied to us by the high-ranking officers (business owner, $\mathrm{MD} / \mathrm{CEO}$, and manager) of these enterprises. All the key informants in this study have university qualifications, the male gender constituted the majority of our sample subjects. We strongly believe that these high-ranking individuals are very knowledgeable about their enterprises' marketing 'strategy' and profitability position. However, like any other research setting, we cannot potentially rule out bias from our respondents. Data collection was from the month of November, 2014 to January, 2015. Some of the returned questionnaires that did not meet our final requirements were expunged from our own database. In all, 119 usable responses were used in the final data analysis. A further look at the collected questionnaires showed that the issue of non-response bias is unlikely to bias the findings of this study given that both early and late respondents appeared to have the same business characteristics in terms of demographics and resource constraints. In the present study (note, output omitted), the major three issues facing these enterprises in general are high/multiplicity of tax rate $(40 \%)$, poor access to finance (27\%), poor coordination of marketing/business activities (17\%), while the rest challenges are about $16 \%$.

\subsection{Study Design Measures}

Scales from previous research were adopted and refined to suit the setting of this research. Moreover, a pilot test was conducted among 20 firms prior to the main study. The outcomes of the pilot study strengthened the need for us to refine some of the existing scales, so as to capture the underlying factors that we intend measuring as well as avoid over-loading 'busy executives' (our respondents) with items that appear to be 'too' repetitively constructed. The measurement scale was anchored on a 5-point Likert scale, ranging from 1 (strongly disagree) to 5 (strongly agree).

The items that capture the construct of brand orientation were adopted from the works of Wong and Merrilees (2008) and Laukkanen et al. (2013) while the market-sensing capability construct was adapted from Fang et al. (2014). The subjective profitability measure was adapted from Baker and Sinkula (2009). The rest of our variables in the questionnaire were either dichotomous or polytomous variables. More precisely, firm size was grouped as either $10-49$ or $50-249$, while staff (employee) motivation and firm's investment in employee training/development were dichotomized variables.

\subsection{Power Analysis and Method of Data Analysis}

With a sample size of 119 participants, a post-hoc power analysis was conducted using the $\mathrm{G}^{*}$ Power 3.1.9.2 software (Faul et al., 2009). The outcome of the power analysis provided a high statistical power ((1- $\beta$ err prob) of .93 with a moderate effect size (Cohen's f2) of .15, alpha-value of .05, sample size of 119 subjects and four predictors. This gives us confidence that the sample size is expected to have a high degree of statistical precision in view of the research model's hypothesized relationships. The rule of thumb is to have a statistical power of at least .8 (Cohen, 1988; Hair et al., 2010).

Given that the current study is an exploratory research, we utilized a variance-based structural equation modeling tool - Partial Least Squares (PLS) approach to unravel the underlying nature of the study's hypothesized relationships. PLS-SEM is a nonparametric approach that is very robust to multivariate non-normality, efficient in handling small sample size, and importantly useful for making predictions as this remains the core goal of this study (c.f. Hair et al., 2012; Wetzels et al., 2009). The software, SMARTPLS 2.0 (Ringle et al., 2005), has been utilized in the computation of our research model. Similarly, we made use of IBM SPSS Statistics version 19 software for the descriptive features of the three latent variables in our study as well as the test of bivariate correlation.

\section{Results}

\subsection{Psychometric Properties of the Research Model}

An investigation of the internal consistency of the latent variables using Cronbach's alpha $(\alpha)$ suggests that all the variables in the model exceed the threshold of 0.7 suggested by Nunnally (1978). More so, as a test for adequate reliability of the measurement constructs, we found out that all the composite reliabilities (CR) of the constructs in the model are within the range of .86 to .94 , thus further confirming the internal consistency of the research constructs. Moreover, to confirm the validity of our model (refer to Table 1), we used the average variance extracted (AVE) of each of the constructs in the model to check for both convergent and divergent validity. All AVEs exceeded the cutoff value of .5 as suggested by Hair et al. (2010). Further diagnostic checks equally pointed at satisfactory convergent and divergent validity of the research constructs.

In addition, using the bootstrapping algorithm available in the SmartPLS software with 1000 bootstrap samples (no sign changes) and 119 cases (sample size), all the outer loadings of the indicators are statistically significant $(p<.01)$. For the full model (both theoretical and control variables), we got an R-squared value of .557 (see Table 1). By and large, the research model's global Goodness-of-Fit (GoF) index is about .49. This means that the research model is able to account for 49 percent of achievable fit, thus exceeding the suggested baseline value of .36 for large effect sizes of R-squared (Tenenhaus et al., 2005). The model's predictive relevance (Stone-Geisser's $\mathrm{Q}^{2}$ ) using the blindfolding procedure with an omission distance of 7 is .363. In line with the suggestion of (Hair et al., 2012), we relied on the output derived from the construct cross-validated redundancy (Stone-Geisser's $\mathrm{Q}^{2}$ ) instead of the construct crossvalidated commonality. To come to the point, the $\mathrm{Q}^{2}$ value of 
.363 suggests that the exogenous constructs in the model have a large predictive relevance for the profitability construct. By and large, our inner model evaluation as well as an evaluation of the structural model appears to suggest that our model is appropriate for the predictive purpose of the current study. Please refer to Table 1 for further details of the model.

Table 1. Model's Psychometric Properties

\begin{tabular}{cccccc}
\hline & Mean (SD) & AVE & CR & $\alpha$ & SFL (range) \\
\hline BO & $3.324(.803)$ & .804 & .942 & .92 & $.734-.955$ \\
\hline MKTSC & $3.555(.654)$ & .838 & .912 & .807 & $.914-.917$ \\
\hline PROFIT & $3.207(.694)$ & .68 & .86 & .751 & $.581-.932$ \\
\hline BO*MKTSC & - & .749 & .96 &. N/A & $.79-.938$ \\
\hline
\end{tabular}

R2 for model with only control variables-> .414

R2 for model with only theoretical variables $->.473$

R2 for full research model $->.557$

Model Predictive Relevance (CV-Redundancy) - Stone-Geisser's $\mathrm{Q}^{2}=.363$

$\mathrm{GOF}=.488$

\begin{tabular}{|c|c|c|c|c|}
\hline & $\mathrm{BO}$ & MKKTSC & BO*MKTSC & PROFIT \\
\hline $\mathrm{BO}$ & .897 & & & \\
\hline MKTSC & .51 & .915 & & \\
\hline BO*MKTSC & -.441 & -.261 & .865 & \\
\hline PROFIT & .552 & .633 & -.284 & .825 \\
\hline
\end{tabular}

Source: Authors' output extracted from SmartPLS

\subsection{Outcomes of Hypotheses Testing}

Based on the analysis of the research model (see Fig. 1), we can confirm that $\mathrm{BO}(\beta=.193, \mathrm{t}=2.057, p<.05)$ and MKSC $(\beta=.305, \mathrm{t}=3.358, p<.001)$ contribute significantly to the profitability of SMEs in the context of the financial services sector. These results lend support to $\mathrm{H} 1$ and $\mathrm{H} 2$ respectively.

Further, to check if enterprises that practice $\mathrm{BO}$ are likely to equally possess MKTSC, and vice versa (i.e., BO and MKTSC covary together), the result of bivariate (Pearson) correlation analysis $(\mathrm{r}(117)=.198, \mathrm{p}<.05)$ provides support for H3; although the relationship is relatively weak (see Fig. 1).

Contrariwise, we do not have statistical support for $\mathrm{H} 3 \mathrm{~b}$ ( $\beta=-.071, \mathrm{t}=1.015, p>.05$ ), thus indicating that the synergistic effect of BO and MKSC may not positively impact on the profitability of these enterprises (see Fig. 1). Even though the coefficient of MKSC appears to be negative, yet it is not statistically different from zero. Thus, we cannot fully comment if it is an inverse relationship or not. Thus, we reject H3b. For further elaboration of the research model, we have attached the original research output in the appendix section (see Appendix A and Appendix B respectively). Moreover, the results of the hypothesis testing $(\mathrm{H} 1, \mathrm{H} 2, \mathrm{H} 3 \mathrm{a}$ and $\mathrm{H} 3 \mathrm{~b})$, that is their path coefficients, are depicted in Fig. 1.

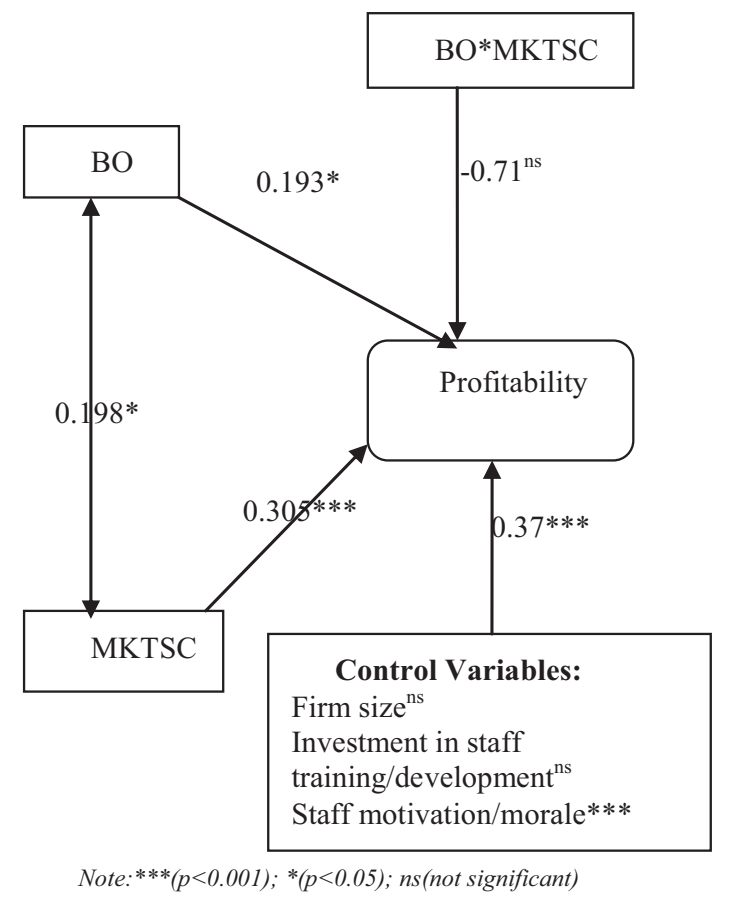

Fig. 1 Research Model showing path coefficients (Source: Authors' output extracted from SmartPLS and SPSS)

\section{Discussion and Conclusions}

It is of import to understand how brand orientation (BO) and market-sensing capability (MKTSC), including the synergistic effect of both contribute to the profitability of SMEs in general considering the resource disadvantages of most of these enterprises, especially those that are situated in the African continent. In the present study, we have clearly demonstrated that BO and MKTSC positively contribute to the profitability position of SMEs that are operating within the Nigerian financial ecosystem.

These findings are not only unique to the study context, but also lend empirical support to similar SMEs-related studies that were conducted in more advanced free-market economies (Laukkanen et al., 2013; Merrilees et al., 2011; Santos-Vijande et al., 2012). In terms of relative importance, MKTSC compared to $\mathrm{BO}$ impacts more on the profitability of these enterprises. It is also interesting to note that $\mathrm{BO}$ and MKTSC covary together.

Taken together, we argue that it is imperative for the custodians of these enterprises to successfully orchestrate the strategic deployment of their intangible resources so as to be able to gain a strong foothold in the country's competitive financial landscape. If such a strategic posture is taken by these enterprises, we believe it would significantly contribute to the financial health of these enterprises. The overwhelming benefits of branding as a strategic marketing tool for firms have long been stressed by distinguished scholars in the marketing field (Aarker, 1996; Kapferer, 2008; Keller and Lehmann, 2006; Urde, 1999). Thus, it is highly imperative for most of the SMEs in the Nigerian financial intermediation sector to develop an 'in-house' branding culture that equally takes into cognizance 'local' market conditions, and more particularly employee involvement. In the same 
vein, for enterprises to become more financially viable in this service sector, they must develop in-house core competence(s)in order to make them more proactive rather than just being reactive to changes in the marketplace (Narver et al., 2004). Thus, enterprises that seek to become more proactive and financially viable must seek to develop an outside-in market capability, particularly that of market-sensing capability. Market-sensing capability is obviously a strategic lever for enterprises that seek to understand and/or adjust to the ongoing market dynamics in their respective industries, thus making these enterprises to be more forward-looking in the marketplace (Day, 1994).

However, we equally found out that the complementarity between BO and MKTSC appears to have a 'null' effect on SMEs profitability. Perhaps, we may infer that these enterprises are still struggling to simultaneously integrate both strategic resources into their marketing practices (or activities). Thus, it might not be too surprising of the insignificant effect on the profitability of these enterprises. In a way, a lack of understanding of how this could be done might equally prove to be a costly venture especially for those SMEs with a short-term focus. SMEs' owner-managers that perhaps assume the simultaneity (or co-alignment) of BO and MKTSC will yield instant marketing and/or financial success should be aware that such a strategic marketing move can only pay off by creating superior customer value proposition in the marketplace.

A further look at the research model shows that one of the control variables, employee motivation is a significant contributor to SMEs profitability. More importantly, SMEs in the financial intermediation sector must seek ways of motivating their workforce. We suggest that high-performing staff should be encouraged to purchase the 'private shares' of these organisations. We believe doing this could create an enviable ownership spirit and camaraderie among the staff of these enterprises, and in turn build the right capabilities that are needed for these enterprises to thrive financially in the marketplace.

To sum up, the present study has shown that SMEs profitability in the context of an African financial intermediation sector is highly likely to be dependent on brand orientation and market-sensing capability as well as having a motivated workforce in place. To the best of our knowledge, this study is arguably the first empirical work to establish a direct path between BO, MKTSC and profitability in the context of SMEs in the financial intermediation sector.

Notwithstanding the outcomes of our findings, we have only demonstrated an associational effect, but not causality among the variables covered in our study. This identified gap in the present study calls for a longitudinal survey in future studies. To improve the generalizability of our findings, researchers that are interested in this context area could extend these findings to other service sectors. It is also important to increase the sample size, thus in subsequent research, our research team is likely to have a larger sample size in a bid to further extend the generalizability of the findings of this research paper. In concluding, our paper has shed some light on the contributions of brand orientation, market-sensing capability and motivated workforce to SMEs profitability in the financial intermediation sector of an African economy, precisely that of Nigeria. It is our hope that SMEs' owner-managers irrespective of the service sector their businesses belong to will find this study useful to a certain level, more especially those SMEs that desire to have a sustainable long-term growth and profitability in the marketplace. The instrument used for this study is available on request.

\section{Acknowledgements}

The author wishes to acknowledge the financial support received from IGA/FaME/2015/039.

\section{References}

Aaker, D. A. (1996) Building Strong Brands. New York: The Free Press.

Baker, W. E., Sinkula, J. M. (2009) The Complementary Effects of Market Orientation and Entrepreneurial Orientation on Profitability in Small Businesses. Journal of Small Business Management. 47 (4). pp. 443-464. DOI: 10.1111/j.1540-627x.2009.00278.x

Balmer, J. M. T. (2013) Corporate brand orientation: What is it? What of it? Journal of Brand Management. 20 (9). pp. 723-741. DOI: $10.1057 / \mathrm{bm} .2013 .15$

Balmer, J. M. T., Greyser, S. A. (2006) Corporate marketing: Integrating corporate identity, corporate branding, corporate communications, corporate image and corporate reputation. European Journal of Marketing. 40 (7/8). pp. 730-741. DOI: 10.1108/03090560610669964

Barney, J. B. (2001) Is the resource-based „,view” a useful perspective for strategic management research? Yes. Strategic Management Journal. 26 (1). pp. 41-56. DOI: 10.2307/259393

Baumgarth, C. (2010) "Living the brand": brand orientation in the businessto-business sector. European Journal of Marketing. 44 (5). pp. 653-671. DOI: $10.1108 / 03090561011032315$

Cohen, J. (1988) Statistical Power Analysis for the Behavioral Sciences. Hillsdale, NJ: Lawrence Erlbaum Associates. DOI: 10.4324/9780203771587

Cook, P., Nixson. F. (2000) Finance and Small and Medium-Sized Enterprise Development. Finance and Development Research Programme Working Paper Series 14. University of Manchester. [Online] Available from: http:// www.gdrc.org/icm/micro/fin-sme.html [Accessed: 13th January 2015]

Day, G. S. (1994) The capabilities of market-driven organizations. Journal of Marketing. 58 (4). pp. 37-52. DOI: 10.2307/1251915

Day, G. S. (2002) Managing the market learning process. Journal of Business \& Industrial Marketing. 17 (4). pp. 240-252. DOI: $10.1108 / 08858620210431651$

Fang, S.-R., Chang, E., Ou, C.-C., Chou, C.-H. (2014) Internal market orientation, market capabilities and learning orientation. European Journal of Marketing. 48 (1/2). pp. 170-192. DOI: 10.1108/ejm-06-2010-0353

Faul, F., Erdfelder, E., Buchner, A., Lang, A.-G. (2009) Statistical power analyses using $\mathrm{G}^{*}$ Power 3.1: Tests for correlation and regression analyses. Behavior Research Methods. 41 (4). pp. 1149-1160. DOI: $10.3758 /$ brm.41.4.1149

Gromark, J., Melin, F. (2011) The underlying dimensions of brand orientation and its impact on financial performance. Journal of Brand Management. 18 (6). p. 394-410. DOI: 10.1057/bm.2010.52

Hair, J.F., Black, W.C., Babin, B.J., Anderson, R.E. (2010) Multivariate Data Analysis. New Jersey: Pearson Prentice Hall. 
Hair, J. F., Sarstedt, M., Ringle, C. M., Mena, J. A. (2012) An assessment of the use of partial least squares structural equation modeling in marketing research. Journal of the Academy Marketing Science. 40 (3). pp. 414 433. DOI: 10.1007/s11747-011-0261-6

Huang, X., Brown, A. (1999) An analysis and classification of problems in small business. International Small Business Journal. 18 (1). pp. 73-85. DOI: $10.1177 / 0266242699181004$

Kapferer, J.-N. (2008) The new strategic brand management: creating and sustaining brand equity long term. London: Kogan Page Limited.

Keller, K. L., Lehmann, D. R. (2006) Brands and branding: research findings and future priorities. Marketing Science. 25 (6). pp. 740-759. DOI: $10.1287 / \mathrm{mksc} .1050 .0153$

Kotler, P., Keller K. (2006). Marketing Management. Upper Saddle River, NJ: Prentice Hall

Krake, F.B.G.J.M. (2005) Successful brand management in SMEs: a new theory and practical hints. Journal of Product \& Brand Management. 14 (4). pp. 228-238. DOI: 10.1108/10610420510609230

Laukkanen, T., Nagy, G., Hirvonen, S., Reijonen, H., Pasanen M. (2013) The effect of strategic orientations on business performance in SMEs: A multigroup analysis comparing Hungary and Finland. International Marketing Review. 30 (6). pp. 510-535. DOI: 10.1108/imr-09-2011-0230

Merrilees, B., Rundle-Thiele, S., Lye, A. (2011) Marketing capabilities: Antecedents and implications for B2B SME performance. Industrial Marketing Management. 40 (3). pp. 368-375. DOI: 10.1016/j.indmarman.2010.08.005

Mitchell, R., Hutchinson, K., Bishop, S. (2012) Interpretation of the retail brand: an SME perspective. International Journal of Retail \& Distribution Management. 40 (2). pp. 157-175. DOI: 10.1108/09590551211201883

Morgan, N. A., Slotegraaf, J. A., Vorhies, D. W. (2009) Linking marketing capabilities with profit growth. International Journal of Research in Marketing. 26 (4). pp. 284-293. DOI: 10.1016/j.ijresmar.2009.06.005

Narver, J. C., Slater, S. F., MacLachlan, D. L. (2004) Responsive and proactive market orientation and new product success. Journal of Product Innovation Management. 21 (5). pp. 334 47. DOI: 10.1111/j.0737-6782.2004.00086.x

Ngo, L. V., O’Cass, A. (2012) Performance implications of market orientation, marketing resources, and marketing capabilities. Journal of Marketing Management. 28 (1-2).pp. 173-187. DOI: 10.1080/0267257x.2011.621443

Nunnally, J. C. (1978) Psychometric theory. New York: McGraw-Hill.

Ogbonna, B.U., Ogwo, E.O. (2013) Market orientation and corporate performance of Insurance firms in Nigeria. International Journal of Marketing Studies. 5 (3). pp. 104-116. DOI: 10.5539/ijms.v5n3p104

Reid, M., Luxton, S., Mavondo, F. (2005) The Relationship between Integrated Marketing Communication, Market Orientation, and Brand Orientation. Journal of Advertising. 34 (4). 11-23. DOI: 10.1080/00913367.2005.10639210

Ringle, C.M., Wende, S., Will, A. (2005) SmartPLS 2.0. Hamburg: SmartPLS. [Online] Available from: http://www.smartpls.com [Accessed: 10th April 2014]

Santos-Vijande, L., Sanzo-Pérez, M. J., Gutiérrez, J. A. T., Rodríguez, N. G. (2012) Marketing Capabilities Development in Small and Medium Enterprises:Implications for Performance. Journal of CENTRUM Cathedra. 5 (1). pp. 24-42. DOI: 10.7835/jcc-berj-2012-0065

Serrasqueiro, Z. A., Nunes, S. P. (2008) Performance and Size: Empirical Evidence from Portuguese SMEs. Small Business Economics. 31 (2). pp. 195-217. DOI: 10.1007/s11187-007-9092-8

SMEDAN/NBS. (2010) Survey Report on Micro, Small and Medium Enterprises (MSMEs) in Nigeria, 2010. [Online] Available from: www.nigerianstat.gov.ng/pages/download/67 [Accessed: 11th December 2014]

Storey, D. J., Westhead, P. (1994) Management Training and Small Firm Performance: A Critical Review. Warwick Business School Small and Medium
Enterprise Centre Working Paper No. 18. [Online] Available from: http://www2.warwick.ac.uk/fac/soc/wbs/research/ei/research/working papers/wp18_-_management_training_small_firm_performance_a critical_review.pdf [Accessed: 13th January 2015]

Teece, D. J. (2007) Explicating Dynamic Capabilities: The Nature and Microfoundations of (Sustainable) Enterprise Performance. Strategic Management Journal. 28 (13). pp. 1319-1350. DOI: 10.1002/smj.640

Tenenhaus, M., Vinzi, V. E., Chatelin, Y.-M., Lauro, C. (2005) PLS Path Modeling. Computational Statistics and Data Analysis. 48 (1). p. 159-205.

Urde, M. (1999) Brand orientation: A mindset for building brand into strategic resources. Journal of Marketing Management. 15 (1-3). pp. 117-133. DOI: 10.1362/026725799784870504

Wetzels, M., Odekerken-Schröder, G., Van Oppen, C. (2009) Using PLS path modeling for assessing hierarchical construct models: guidelines and empirical illustration. MIS Quarterly. 33 (1). pp. 177-195.

Wong, H. Y., Merrilees, B. (2005) A brand orientation typology for SMEs: a case research approach. Journal of Product \& Brand Management. 14 (3). pp. 155-162. DOI: 10.1108/10610420510601021

Wong, H. Y., Merrilees, B. (2008) The Performance Benefits of Being Brand Oriented. Journal of Product \& Brand Management. 17 (6). pp. 372 383. DOI: 10.1108/10610420810904112

\section{APPENDIX A- PLS-SEM Pictorial Output of Research Model}

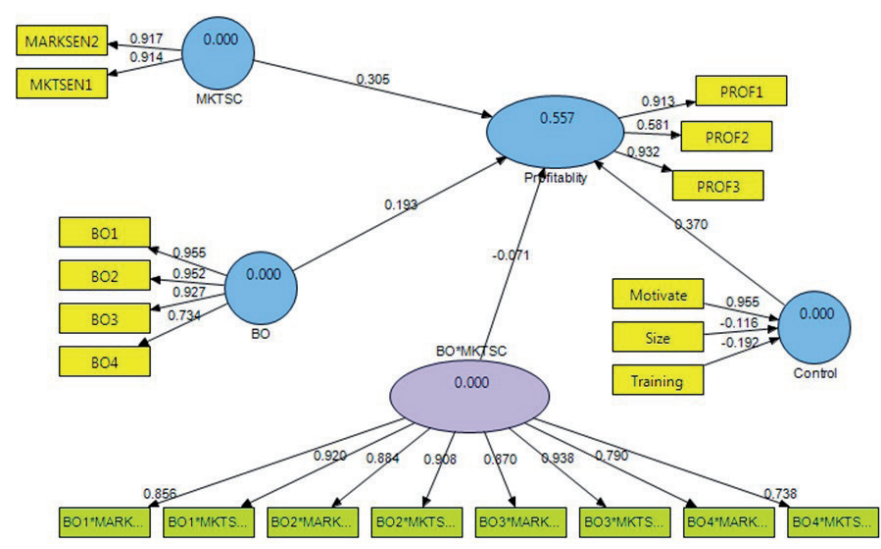

Source: Authors' output extracted from SmartPLS

\section{APPENDIX B- Bivariate Correlation of BO and MKTSC}

\begin{tabular}{cccc}
\hline & & MKTSC & BO \\
\hline \multirow{2}{*}{ MKTSC } & Pearson Correlation & 1 & $.198^{*}$ \\
& Sig. (2-tailed) & & .031 \\
& Pearson Correlation & $.198^{*}$ & 1 \\
BO & Sig. (2-tailed) & .031 & \\
\cline { 2 - 4 } & N & 119 & 119 \\
\hline
\end{tabular}

Source: Authors' output extracted from SPSS 